Research Article

\title{
Theoretical Analysis of Bulletproof Capability of Multilayer Ceramic Composites Subjected to Impact by an Armor Piercing Projectile
}

\author{
Yu-Liang Chen, ${ }^{1,2}$ Wen-Kuan Huang, ${ }^{1}$ and Jau-Nan Yeh $\mathbb{D}^{1,2}$ \\ ${ }^{1}$ Department of Power Vehicle and Systems Engineering, Chung Cheng Institute of Technology, National Defense University, \\ Taoyuan, Taiwan \\ ${ }^{2}$ System Engineering and Technology Program, National Chiao Tung University, Hsinchu, Taiwan
}

Correspondence should be addressed to Jau-Nan Yeh; c31000403@gmail.com

Received 21 March 2021; Accepted 17 June 2021; Published 24 June 2021

Academic Editor: Aniello Riccio

Copyright ( $\odot 2021$ Yu-Liang Chen et al. This is an open access article distributed under the Creative Commons Attribution License, which permits unrestricted use, distribution, and reproduction in any medium, provided the original work is properly cited.

Inspired by the theories of Tate and Zaera, a theoretical analysis model including the erosion of the projectile, the cracking of ceramic composites, and the deformation of metal backplate was established in this study to investigate the bulletproof capability of the ceramic composites under impact by an armor piecing projectile (AP). The analysis results were verified by ballistic tests. As for the ceramic composites, the volume of the cracked ceramic conoid and the change in the compressive strength were included. Regarding the deformation of the metal backplate, the plastic deformation work, the external work, and the conservation of kinetics were considered. Based on the thickness of the target plate, failure modes were separated into the plug type and the petal type. The ordinary differential equation solver of MATLAB, ode45, was adopted to solve relevant ordinary differential equations. In this study, the powder metallurgy was used to produce the $\mathrm{Al}_{2} \mathrm{O}_{3} / \mathrm{ZrO}_{2}$ multilayered ceramic composites of three layers; each layer was $3 \mathrm{~mm}$ in thickness. The ceramic composites were paired with a backplate made of 6061-T6 aluminum alloy with a thickness of either $1 \mathrm{~mm}$ or $4 \mathrm{~mm}$. The ballistic tests were executed by using $0.30^{\prime \prime}$ AP projectiles to impact the specimens. The results from theoretical model and ballistic tests were compared and shown consistent in the field of residual velocity, residual bullet mass, and the failure modes of the metal backplate.

\section{Introduction}

No single material can exert optimal effectiveness as protective armor. Composite materials composed of two or more materials can address the weaknesses of any single material. Ceramics exhibit superior protective performance with low density, high strength, and high hardness. Therefore, lightweight, bulletproof composite armors composed of ceramics and metals are widely employed by various countries [1].

In a composite plate, the ceramic front plate and the tough metal backplate have different values of elastic modulus, hardness, and density; these differences cause impedance mismatches in the waves between the layers. Under the impact of a projectile, the reflective tensile wave causes severe damage to the ceramic front plate. In addition, the use of unsuitable adhesive usually results in delamination of layers, significantly reducing the ceramic armor's ability to resist multiple impacts. To reduce the delamination of the ceramic plate and the metal plate and to reduce the damage from reflection waves, functionally graded materials (FGMs) are utilized.

To date, several theoretical models have described ceramic-metal composite target plates struck by projectiles. However, most models only describe target plates with ceramics as the single component. This study established theoretical models of projectiles impacting functionally graded ceramics-aluminum alloy composite target plates and compared the theoretical results with the experimental results. 


\section{Theoretical Analysis Model}

2.1. Simplified Models for Graded Ceramics-Aluminum Alloy Composite Target Plates under Bullet Impact. The impact of a bullet on a ceramic-aluminum alloy composite target plate is a complex process. If the bullet impacts the target plate at a certain velocity, the stress at the tip of the bullet rapidly increases as soon as the bullet touches the surface of the plate; this results in the erosion of the bullet. Some metal from the tip of the bullet separates from the rest of the bullet; thus, the length of the bullet reduces. The compressive stress at the point of contact on the ceramic surface is larger than the compression strength of the ceramic, and the ceramic near the contact area starts to crack. The tensile stress wave causes radial cracks and tapered cracks to expand along the impact direction. When the compressive stress wave is transferred from the contact surface to the back of the ceramic plate, it is reflected by the metal backplate and produces a tensile stress wave, causing tensile cracks in the ceramic. The cracks in the ceramic expand, eventually forming a broken conoid, called a ceramic conoid. The deformed bullet and the cracked ceramic conoid both affect the metal backplate; they either tear a hole in the backplate or deform it with a hump.

Therefore, the erosion of the bullet, the cracking of the ceramic, and the deformation of the metal backplate are all critical problems. This study is divided into three parts. Regarding the question of a bullet impacting a ceramicmetal composite, this study constructed a theoretical model (Figure 1), which is described as follows.

(1) The bullet model: assume that the projectile is a cylindrical flat-nose bullet, with an initial length of $L_{0}$, a diameter of $D_{P}$, and a density of $\rho_{P}$, that the initial impact velocity is $V_{0}$, that the dynamic yield strength is $Y_{P}$, and that the elastic modulus is $E_{P}$. During the impact process, the deformation of the bullet is disregarded, and only the erosion of the mass (length) is considered.

(2) The ceramic model: ceramic materials are brittle. Assume that the thickness of each layer of the graded ceramic is $\left(h_{C} / 3\right)$, and the total thickness is $h_{C}$. The densities of the layers are $\rho_{C 1}, \rho_{C 2}$, and $\rho_{C 3}$, respectively, and the average density $\rho_{C}=\left(\left(\rho_{C 1}+\right.\right.$ $\left.\left.\rho_{C 2}+\rho_{C 3}\right) / 3\right)$. The elastic modulus values of the layers are $E_{C 1}, E_{C 2}$, and $E_{C 3}$, respectively, and the equivalent elastic modulus is $\left(3 / E_{C}\right)=\left(\left(1 / E_{C 1}\right)+\right.$ $\left.\left(1 / E_{C 2}\right)+\left(1 / E_{C 3}\right)\right)$. Their Poisson's ratios are $v_{C 1}$, $v_{C 2}$, and $v_{C 3}$, respectively. Their dynamic compressive strengths are $Y_{C 1}, Y_{C 2}$, and $Y_{C 3}$, respectively, and their average dynamic compressive strength is $Y_{C}=\left(\left(Y_{C 1}+Y_{C 2}+Y_{C 3}\right) / 3\right)$.

(3) The metal backplate model: the backplate is made of elastic materials with a thickness of $h_{b}$, a density of $\rho_{b}$, an elastic modulus of $E_{b}$, and a yield strength of $Y_{b}$.

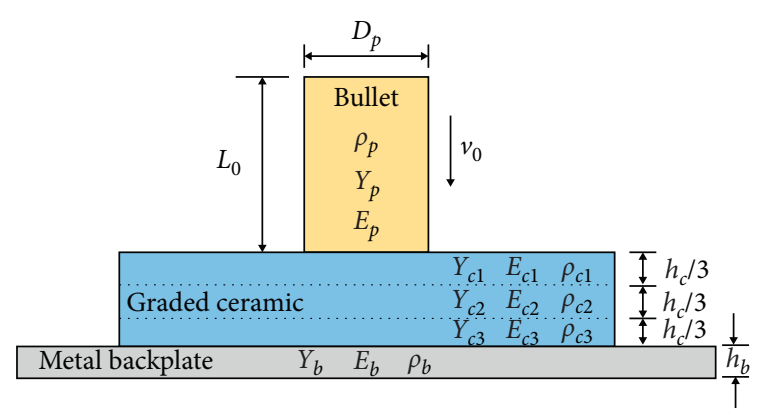

FIgURE 1: Simplified one-dimensional analysis model of a bullet impacting a ceramics-metal plate.

\subsection{The Analysis Model of a Graded Ceramics-Metal Composite Target Plate under the Impact of a Bullet}

2.2.1. Bullet Model. During 1964 and 1966, Alekseevskii and Tate each proposed revised models of Bernoulli's equation [2-4]. The revised fluid mechanics equation is called the Tate equation, presented as equation (1), where $\rho_{P}$ is the projectile density, $\rho_{t}$ is the target plate density, $V$ is the bottom velocity of the projective body, $U$ is the velocity at which the projectile penetrates, $Y_{P}$ is the dynamic yield strength of the material of the projectile, and $R_{t}$ is the resistance or the dynamic yield strength of the target plate material.

$$
Y_{P}+\frac{1}{2} \rho_{P}(V-U)^{2}=R_{t}+\frac{1}{2} \rho_{t} U^{2}
$$

The first stage, as shown in Figure 2, refers to the period after the bullet has impacted the ceramic layer $(t=0)$ but before the ceramic has fractured to form a complete ceramic conoid $\left(t<t_{\text {conoid }}\right)$. Assume that during this period, the bullet is static $(U=0)$, and the interface velocity of the ceramic layers and metal backplate is also zero $(W=0)$. At this time, the rear of the bullet still has the impact velocity $(V)$. Because an armor piercing (AP) shell is made of steel, given that its failure mode is erosion without deformation, the length of the bullet will erode at the velocity of $V-U$, as presented in the following equation:

$$
\frac{\mathrm{d} L}{\mathrm{~d} t}=-(V-U)
$$

The equation of motion at this stage is

$$
\frac{\mathrm{d} V}{\mathrm{~d} t}=\frac{Y_{P}+(1 / 2) \rho_{P} V^{2}}{-\rho_{P} L} .
$$

When $t=t_{\text {conoid, }}$ the internal damaged volumes of the ceramic layers have expanded to the entire ceramic structure (Figure 3). Starting at this moment, ceramic mass can move along the impact direction $(U>0)$. At this moment, $U=V_{r}$, where $V_{r}$ is the residual velocity of the bullet. In addition, the length of the bullet $L=L_{r}$. The bullet will no longer be eroded, so the bullet can be seen as a rigid body. When $U=0$ changes to $U=V_{r}$, it signifies the end of the first stage, the static stage.

The equation of motion at the second stage is 


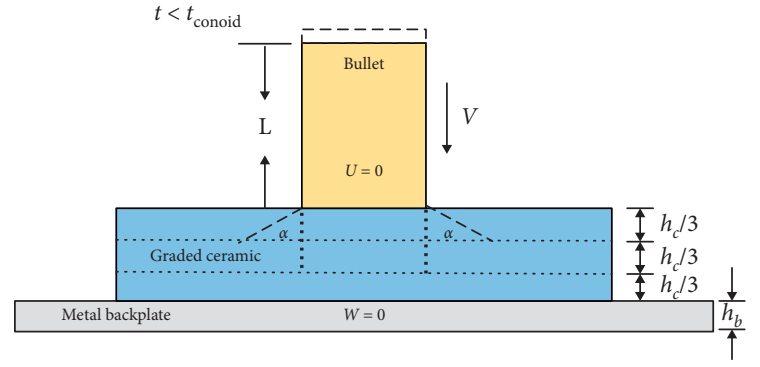

FIGURE 2: Simplified one-dimensional model of a bullet impacting a ceramic-metal plate during the first stage.

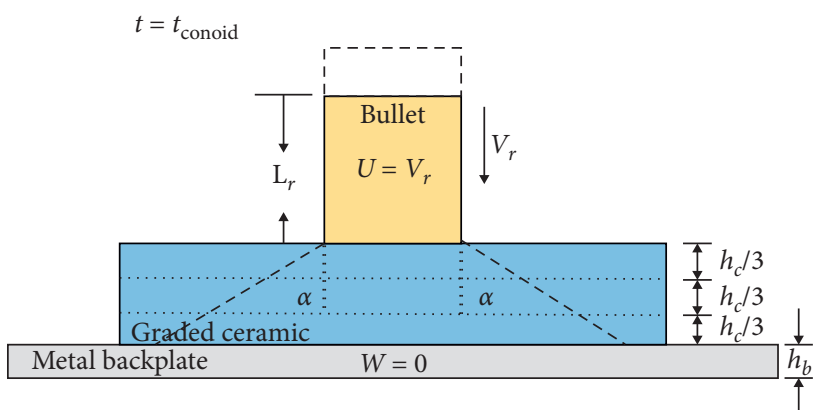

Figure 3: Simplified one-dimensional model of a bullet impacting a ceramic-metal plate when the first stage ends.

$$
\frac{\mathrm{d} V}{\mathrm{~d} t}=\frac{Y_{C}+1 / 2 \rho_{C} V^{2}}{-\rho_{P} L_{r}}
$$

Studies by Wilkin and Den Reijer [5, 6] revealed that the cracking of ceramics mainly happened in the stage immediately after contact. Cracked ceramic layers reduce the compressive strength of the ceramic structure, making it easier for the bullet to penetrate. Den Reijer analyzed ceramic conoids and assumed that the compressive stress wave penetrated the entire ceramic structure from the point of impact, engendering cracks in the ceramic layers. When the cracks expand to the entire ceramic structure, a ceramic conoid forms. The time at which a ceramic conoid forms is

$$
t_{\text {conoid }}=\frac{h_{C}}{u_{\text {long }}}+\frac{h_{C}}{V_{\text {crack }}}=\frac{6 h_{C}}{u_{\text {long }}},
$$

where $h_{c}$ is the thickness of the ceramic conoid, $u_{\text {long }}$ is the longitudinal stress wave velocity, and $V_{\text {crack }}$ is the radial cracking velocity. Therefore, the time at which a ceramic conoid forms in the functionally graded ceramic plate is

$$
\begin{aligned}
t_{\text {conoid }} & =t_{c 1}+t_{c 2}+t_{c 3} \\
& =\frac{2 h_{C}}{u_{1}}+\frac{2 h_{C}}{u_{2}}+\frac{2 h_{C}}{u_{3}},
\end{aligned}
$$

where $t_{c 1}, t_{c 2}$, and $t_{c 3}$ are the times at which the first, second, and third layers of a ceramic conoid are formed, respectively; and $u_{1}, u_{2}$, and $u_{3}$ are the longitudinal wave velocities of the first, second, and third layers of the functionally graded ceramic, respectively.
2.2.2. Ceramic Conoid Model. The theoretical analysis of Zaera and Galvez [7] was adopted in this study. The velocity field in the ceramic conoid is not a constant. Rather, at the surface where the bullet contacts the ceramic, the velocities of the ceramic particles have the same magnitude as the penetration velocity $U$. The velocity rapidly declines at a constant slope along the direction of the impact, and when it reaches the interface between the ceramic structure and the metal backplate, the velocity becomes $W$. Finally, the velocity in the metal backplate is generally a constant (Figure 4). Therefore, the theoretical equations (7) to (9) are as follows:

$$
\begin{aligned}
D_{C} & =D_{P}+2 h_{c} \tan \alpha, \\
\frac{\mathrm{d} h_{c}}{\mathrm{~d} t} & =-U+W, \\
\frac{\mathrm{d} D_{C}}{\mathrm{~d} t} & =2 \tan \alpha(-U+W),
\end{aligned}
$$

where $\alpha$ is the included angle between the edge of the ceramic conoid and the impact direction, $h_{c}$ is the thickness of the ceramic conoid, $D_{C}$ is the diameter of the bottom of the ceramic conoid, $D_{P}$ is the diameter of the bullet, and $W$ is the velocity in the metal backplate.

As for the included angle $\alpha$ of the ceramic conoid, according to the experiments of Den Reijer [6], $\alpha$ is generally between $60^{\circ}$ and $65^{\circ}$. To facilitate calculation, this study assumed $\alpha=63.44^{\circ}$; therefore, $\tan \alpha=2$.

Assume that the velocity distribution in the ceramic conoid is linear, and the momentum of the ceramic conoid is

$$
P_{C}=\frac{1}{48} \pi \rho_{C} h_{c}\left[U\left(3 D_{P}^{2}+D_{C}^{2}+2 D_{P} D_{C}\right)+W\left(D_{P}^{2}+3 D_{C}^{2}+2 D_{P} D_{C}\right)\right] .
$$

However, the active force at the top of the ceramic conoid is $\pi\left(D_{P} / 2\right)^{2} Y_{C}$, and that at the bottom is $\pi\left(D_{C} / 2\right)^{2} f_{b}$ (Figure 5). According to the conservation of momentum, the momentum change rate of the ceramic conoid is

$$
\frac{\mathrm{d} P_{C}}{\mathrm{~d} t}=\pi\left(\frac{D_{P}}{2}\right)^{2} Y_{C}-\pi\left(\frac{D_{C}}{2}\right)^{2} f_{b} .
$$

Therefore,

$$
\begin{aligned}
& \frac{\partial P_{C}}{\partial h_{c}} \frac{d h_{c}}{d t}+\frac{\partial P_{C}}{\partial D_{C}} \frac{d D_{C}}{d t}+\frac{\partial P_{C}}{\partial U} \frac{d U}{d t}+\frac{\partial P_{C}}{\partial W} \frac{d W}{d t} \\
& =\frac{1}{4} \pi\left(D_{P}^{2} Y_{C}-D_{C}^{2} f_{b}\right),
\end{aligned}
$$

where $Y_{C}$ is the compressive strength of cracked ceramic and $f_{b}$ is the active force of the metal backplate on the ceramic structure.

The cracks in the ceramic layers reduce the compressive strength of the ceramic structure. Wilkins [5] studied the change in the strength of cracked ceramics to obtain the relationship between the strength of a cracked ceramic conoid and that of an intact ceramic structure. Given that the strength of an intact ceramic structure is $Y_{C 0}$ and that of a 


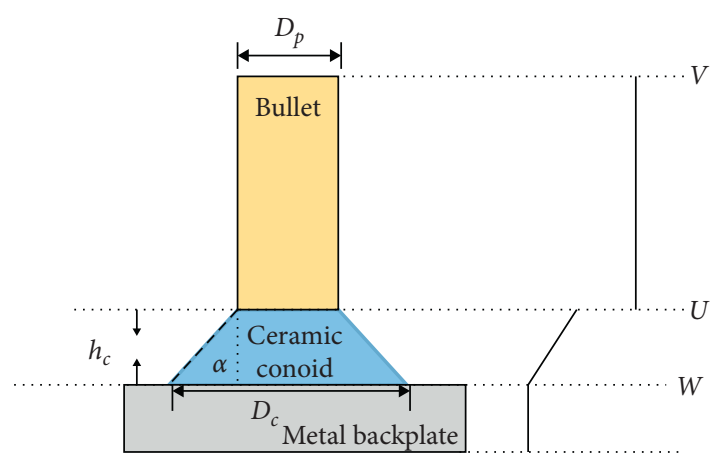

FIgURE 4: Velocity field analysis model.

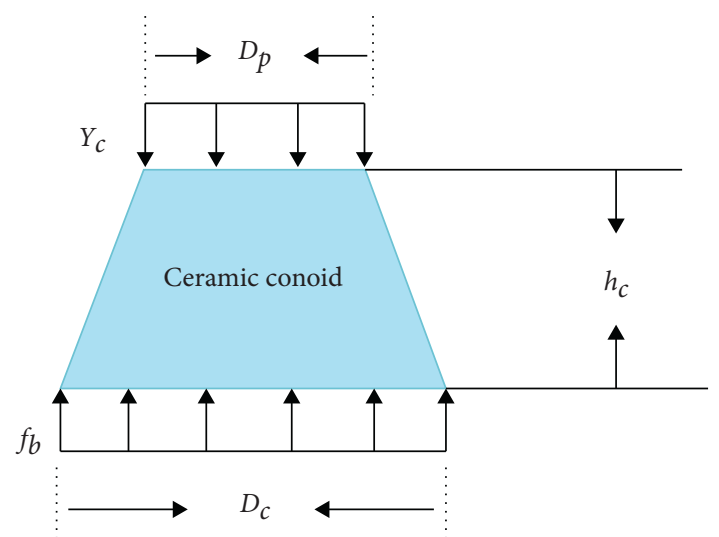

Figure 5: Ceramic conoid model.

cracked ceramic conoid is $Y_{C}$, then the relationship between $Y_{C}$ and the velocities of the ceramic conoid's top $(U)$ and bottom $(W)$ is

$$
Y_{C}=Y_{C 0}\left(\frac{U-W}{U_{0}}\right)^{2}
$$

where $U_{0}$ is the penetration velocity when the crack stage ends. Thus, when $t=t_{\text {conoid, }}$, the penetration velocity of the bullet is $V_{r}$.

2.2.3. Metal Backplate Model. The formalization of the model of the metal backplate can be conducted in accordance with the conservation of energy. Considering the different thickness of metal backplates, two penetration modes may occur when a bullet impacts a plate, the plug type and the petal type [7]. Regarding the plug type, after the first stage, the ceramic conoid is separated from the ceramic plate along crack lines. The eroded bullet and the ceramic conoid work together on the metal backplate, causing tensile and bending deformation (Figure 6). Woodward et al. [8] proposed the plastic deformation equation for the backplate tensile and bending deformation presented here as follows:

$$
E_{j}=\pi h_{b} \delta Y_{b}\left(\frac{2}{3} h_{b}+\frac{1}{2} \delta\right)
$$

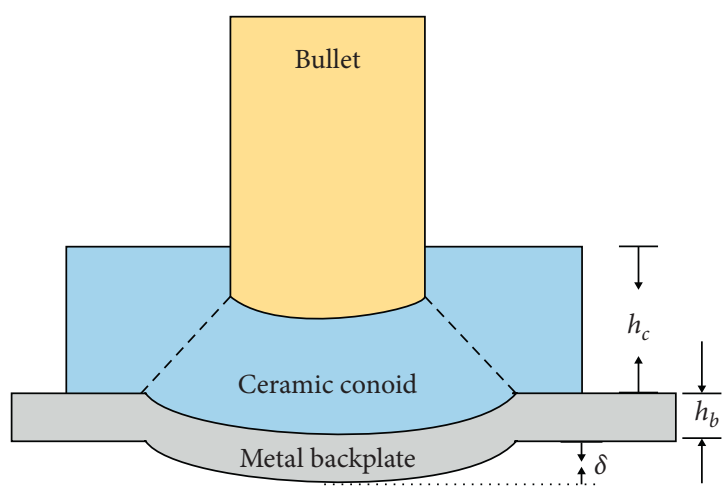

FIgURE 6: Ceramic conoid working on a metal plate.

where $h_{b}$ is the thickness of the metal backplate, $Y_{b}$ is the yield strength of the backplate, $\delta$ is the displacement of the center of the backplate, and $W$ is the velocity of the center of the backplate. Therefore,

$$
\frac{\mathrm{d} \delta}{\mathrm{d} t}=W .
$$

During the deformation process of the metal backplate, the pressure it receives from the ceramic conoid is $f_{b}$, and the work it produces is

$$
T=\pi\left(\frac{D_{C}}{2}\right)^{2} f_{b} \delta
$$

The kinetic energy in the central area of the metal backplate is

$$
E_{K}=\frac{1}{2}\left[\pi\left(\frac{D_{b}}{2}\right)^{2} h_{b} \rho_{b}\right] W^{2},
$$

where $D_{b}$ is the diameter of the deformation area in the center of the metal backplate. Here, we assumed $D_{b}$ equals $D_{C 0}$, the initial diameter of the bottom of the ceramic conoid. According to the conservation of energy,

$$
\frac{\mathrm{d} W}{\mathrm{~d} t}=\frac{f_{b} D_{C}^{2}-4 h_{b} Y_{b}\left((2 / 3) h_{b}+\delta\right)}{D_{b}^{2} h_{b} \rho_{b}} .
$$

According to the results from Zaera and Galvez [7], in this situation, when the penetration velocity $U$ is close to the velocity of the metal $W$, even though the ceramic structure or the metal plate has not been completely penetrated, the target plate has been deformed. Therefore, the standard for failure is $U=W$. In this plug-type penetration mode, the plug and the bullet move forward at the same velocity. This design is suitable for low impact velocity, and in this study, this model was utilized for thick metal backplates.

The second type is the petal type. If the impact velocity is far faster than the ballistic limit velocity, the bullet will completely penetrate the ceramic structure and will contact the metal backplate without causing substantial bending to the backplate. Therefore, equation (16) was modified to show the work and rate of change of work of the bullet on the metal backplate as 


$$
\begin{aligned}
T & =\pi\left(\frac{D_{P}}{2}\right)^{2} Y_{b} \delta, \\
\frac{\mathrm{d} T}{\mathrm{~d} t} & =\frac{1}{4} \pi Y_{b} D_{P}^{2} W .
\end{aligned}
$$

The kinetic energy and rate of change of the kinetic energy in the central area of the metal backplate were adjusted as

$$
\begin{aligned}
E_{K} & =\frac{1}{2} M_{b} W^{2}, \\
\frac{\mathrm{d} E_{K}}{\mathrm{~d} t} & =M_{b} W \frac{\mathrm{d} W}{\mathrm{~d} t} .
\end{aligned}
$$

Similarly, according to the conservation of energy,

$$
\frac{\mathrm{d} W}{\mathrm{~d} t}=\frac{(1 / 4) \pi Y_{b} D_{P}^{2}-\pi h_{b} Y_{b}\left((2 / 3) h_{b}+\delta\right)}{M_{b}},
$$

where the mass of the deformation area in the metal backplate $M_{b}$ is

$$
M_{b}=\frac{1}{4} \pi \rho_{b}\left[D_{b}^{2} h_{b}-D_{p}^{2}\left(h_{b}-h_{b t}\right)\right] .
$$

However, when the thickness of the center of the metal plate is reduced to 0 , the target plate fails, or $h_{b t}=0$. This is a petal-type penetration mode, and in this study, it was employed for thin metal backplates.

\section{Experimental Planning and Design}

A key point in selecting FGM materials is that the coefficients of thermal expansion and sintering condition are similar to each other. Therefore, the ceramics used in this study were composed of high-purity $\mathrm{Al}_{2} \mathrm{O}_{3}$ (99.5\%) and 3 mol\% $\mathrm{Y}_{2} \mathrm{O}_{3}$-stabilized zirconia (3YSZ, 94.4\%) to avoid stress concentration and delamination.

The FGM plates in this study were divided into three layers in the direction of thickness, and the materials had two proportions. Plates with the first material proportion were composed of $\mathrm{Al}_{2} \mathrm{O}_{3}\left(100\right.$ wt.\%) in the first layer, $\mathrm{Al}_{2} \mathrm{O}_{3}$ (90 wt.\%) and $\mathrm{ZrO}_{2}$ (10 wt.\%) in the second layer, and $\mathrm{Al}_{2} \mathrm{O}_{3}$ (80 wt.\%) and $\mathrm{ZrO}_{2}(20$ wt.\%) in the third layer. Plates with the second material proportion were composed of $\mathrm{Al}_{2} \mathrm{O}_{3}\left(100\right.$ wt.\%) in the first layer, $\mathrm{Al}_{2} \mathrm{O}_{3}$ (95 wt.\%) and $\mathrm{ZrO}_{2}$ (5 wt.\%) in the second layer, and $\mathrm{Al}_{2} \mathrm{O}_{3}$ (90 wt.\%) and $\mathrm{ZrO}_{2}(10 \mathrm{wt} . \%)$ in the third layer. The trial ceramics were hexagonal and measured $60 \mathrm{~mm}$ along each side. The thickness of each graded layer was $3 \mathrm{~mm}$; thus, each ceramic structure had a total thickness of $9 \mathrm{~mm}$. The adhesive between the ceramics and the backplate was epoxy resin.

Backplates made of 6061-T6 Al aluminum alloy were adopted, measuring $200 \mathrm{~mm} \times 200 \mathrm{~mm}$ with thicknesses of $1 \mathrm{~mm}$ and $4 \mathrm{~mm}$. In theoretical model calculations, all the other conditions were controlled and only the thickness of the aluminum alloy backplate was different. When the thickness was between $1 \mathrm{~mm}$ and $3 \mathrm{~mm}$, the failure type of the aluminum backplate was more similar to a petal-type failure and could be described using equation (21). However, when the thickness of the backplate was $4 \mathrm{~mm}$ or more, then equation (18) was adequate because the backplate would be of a plug-type failure.

The $0.30^{\prime \prime}$ armor piercing (AP) projectile was adopted to execute ballistic test. To simplify the model, however, flatnose AP slugs were adopted in theoretical analysis, and they were further divided into two types (Table 1). Subsequently, ballistic tests were conducted to verify the theoretical model. The first type of flat-nose AP slugs were equivalent conversed $0.30^{\prime \prime}$ AP bullet to flat-nose slugs with the same mass and diameter, and only the characteristics of the steel were considered. The second type of flat-nose AP slugs were equivalent conversed steel cores of $0.30^{\prime \prime}$ bullet to flat-nose steel-core models with the same mass and diameter.

\section{Experimental Results and Discussion}

4.1. Ballistic Experimental Results. Experimental specimen plates were distinguished into four types: the 10\% 333 FGM + $4 \mathrm{~mm}$ Al backplate, 10\% 333 FGM + $1 \mathrm{~mm} \mathrm{Al} \mathrm{backplate,} \mathrm{5 \%}$ 333 FGM + 4 mm Al backplate, and the 5\% 333 FGM + 1 mm Al backplate. Three repeated experiments were executed on each type of target plate. The prepared specimen and AP projectile are shown in Figure 7 . Table 2 summarizes the experimental results, namely, the average initial velocity, the average final residual velocity, and the residual mass of the bullet for the four types of target plates. Among them, the error of the residual mass of the copper of the bullet was larger than the errors of the other measurements because after the projectile struck, the copper jacket was separated from the steel core; the fragments were irretrievably lost. Figures 8-11 show the experimental results for different experimental plates.

4.2. Theoretical Analysis Results. The material parameters needed in this theoretical model were adopted from Huang's dissertation [9] (Tables 3 5) where the dynamic compressive strength was obtained through dynamic tests using Split-Hopkinson bar measurement.

Using $\rho_{C}=\left(\rho_{C 1}+\rho_{C 2}+\rho_{C 3}\right) / 3,1 / E_{C}=\left((1 / 3) / E_{C 1}\right)+$ $\left((1 / 3) / E_{C 2}\right)+\left((1 / 3) / E_{C 3}\right)$, and $Y_{C}=\left(Y_{C 1}+Y_{C 2}+Y_{C 3}\right) / 3$, this study obtained the parameters of the functionally graded ceramic composites (Table 6).

Differential equations were composed using the aforementioned theories and solved with ode 45 in the MATLAB environment. The obtained $V-t$ trend is illustrated in Figures 12 to 15 .

\section{Comparisons of the Theoretical Model and Experimental Results}

5.1. Comparisons of the Residual Velocity. The comparisons of residual velocities obtained from four types of target plate ballistic experimental results and from the theoretical model are shown in Table 7. Two types of bullet models were used in the theoretical model: the $0.30^{\prime \prime}$ flat-nose AP bullets and the $0.30^{\prime \prime}$ flat-nose steel core AP bullets. The two models were compared to the theoretical models, and the results 
TABLE 1: Bullet model specifications.

\begin{tabular}{|c|c|c|c|c|c|c|}
\hline & Type & Bullet & Mass (g) & $\begin{array}{l}\qquad L_{0} \\
\text { length of the bullet }(\mathrm{cm})\end{array}$ & $\begin{array}{c}D_{P} \\
\text { diameter of the bullet }(\mathrm{cm})\end{array}$ & $\begin{array}{c}\rho_{P} \\
\text { density }\left(\mathrm{g} / \mathrm{cm}^{3}\right) \\
\end{array}$ \\
\hline \multirow[b]{2}{*}{1} & Actual & $0.30^{\prime \prime}$ AP bullet & 10.58 & 3.405 & 0.78 & Steel 7.89 , copper 8.93 \\
\hline & Model & $0.30^{\prime \prime}$ Flat-nose AP bullet & 10.58 & 2.808 & 0.78 & 7.89 \\
\hline \multirow[b]{2}{*}{2} & Actual & $0.30^{\prime \prime}$ AP Steel core & 5.187 & 2.647 & 0.621 & 7.89 \\
\hline & Model & $\begin{array}{l}\text { Flat-nose } \\
\text { AP Steel core }\end{array}$ & 5.187 & 2.172 & 0.621 & 7.89 \\
\hline
\end{tabular}

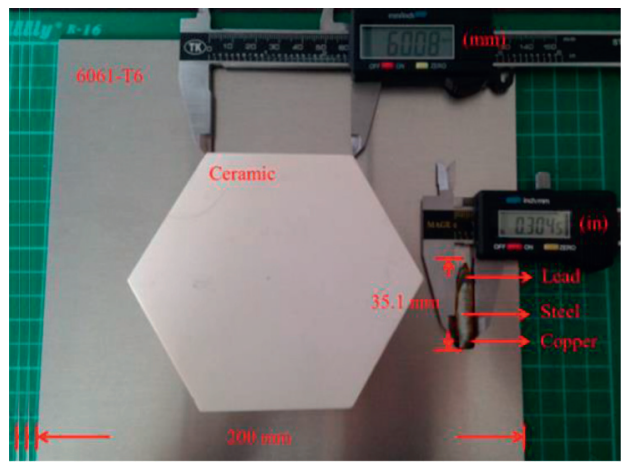

Figure 7: Prepared specimen and $0.30^{\prime \prime}$ AP projectile.

TABLE 2: Ballistic experimental results.

\begin{tabular}{|c|c|c|c|c|c|c|c|}
\hline \multirow[b]{2}{*}{ Number } & \multirow[b]{2}{*}{ Target plate } & \multicolumn{6}{|c|}{ Bullet } \\
\hline & & $\begin{array}{l}\text { Average initial } \\
\text { velocity }(\mathrm{m} / \mathrm{s})\end{array}$ & $\begin{array}{c}\text { Average } \\
\text { residual velocity } \\
(\mathrm{m} / \mathrm{s})\end{array}$ & $\begin{array}{l}\text { Initial mass of } \\
\text { the bullet (g) }\end{array}$ & $\begin{array}{l}\text { Initial steel } \\
\text { mass in the } \\
\text { bullet }(\mathrm{g})\end{array}$ & $\begin{array}{l}\text { Residual steel } \\
\text { mass in the bullet } \\
\text { (g) }\end{array}$ & $\begin{array}{l}\text { Residual copper } \\
\text { mass in the bullet } \\
(\mathrm{g})\end{array}$ \\
\hline 1 & $\begin{array}{c}10 \% 333 \mathrm{FGM}+ \\
4 \mathrm{~mm} \mathrm{Al} \\
\text { backplate }\end{array}$ & 844.0 & 301.7 & 10.58 & 5.187 & 3.379 & 2.249 \\
\hline 2 & $\begin{array}{c}10 \% 333 \mathrm{FGM}+ \\
1 \mathrm{~mm} \mathrm{Al} \\
\text { backplate }\end{array}$ & 850.7 & 489.9 & 10.58 & 5.187 & 3.783 & 4.466 \\
\hline 3 & $\begin{array}{c}5 \% 333 \mathrm{FGM}+ \\
4 \mathrm{~mm} \mathrm{Al} \\
\text { backplate }\end{array}$ & 847.7 & 297.9 & 10.58 & 5.187 & 3.549 & 2.353 \\
\hline 4 & $\begin{array}{c}5 \% 333 \mathrm{FGM}+ \\
1 \mathrm{~mm} \mathrm{Al} \\
\text { backplate }\end{array}$ & 842.8 & 473.7 & 10.58 & 5.187 & 3.787 & 2.785 \\
\hline
\end{tabular}

reflected that the errors of the calculated and the experimental residual velocities of the flat-nose steel core AP models were all below $10 \%$. The errors of the residual velocities of the 0.30 " flat-nose AP model and the ballistic experiments were over $10 \%$, and the error was over $20 \%$ when the thickness of the aluminum alloy backplate was $4 \mathrm{~mm}$. Therefore, the theoretical models of this study were more accurate in describing the flat-nose steel core AP models, for which the theoretical predictions were closer to the ballistic experimental results than the predictions of the $0.30^{\prime \prime}$ flat-nose AP models. The ballistic experimental analysis results reflected that after a bullet hit a target plate, the copper jacket immediately deformed, fragmented, and was separated from the steel core and the majority of the copper remained in the front layer of the target plate.
Consequently, if the theory used the entire mass of the bullet, the results would deviate from the ballistic experimental results. Therefore, the flat-nose steel core AP model was more suitable than the $0.30^{\prime \prime}$ flat-nose AP model.

5.2. Residual Mass Comparison. According to the aforementioned results, the theoretical flat-nose steel core AP model was selected. According to the theoretical model, at the end of the first stage, the length of the bullet was converted to the residual mass of the bullet, and the mass was compared with the ballistic experimental results (Table 8). The table shows that the theoretical residual bullet masses were all higher than the experimental values. When the total thickness of the target plate was $13 \mathrm{~mm}$, 


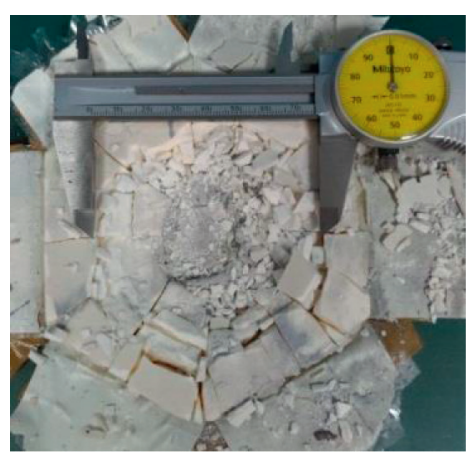

(a)

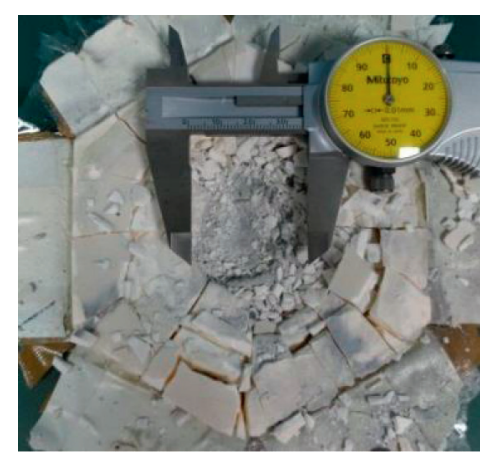

(b)

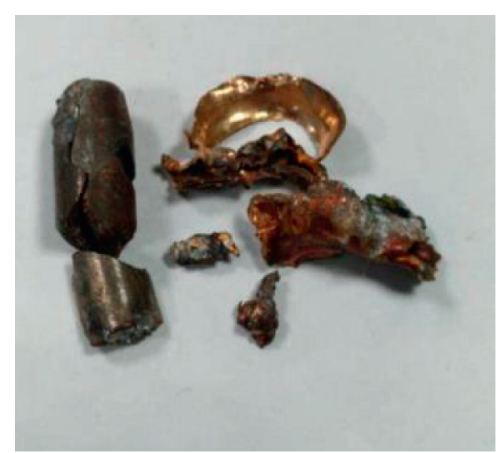

(c)

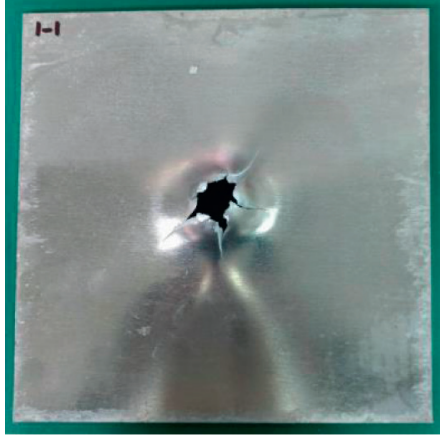

(d)

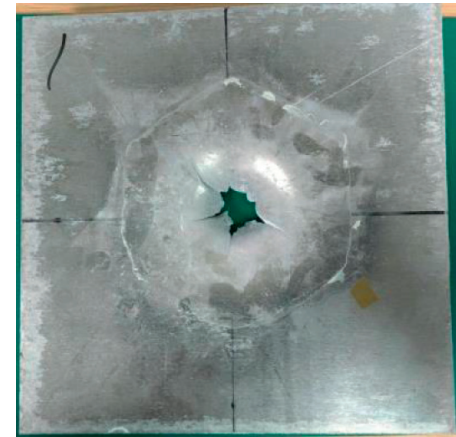

(e)

Figure 8: 10\% 333 FGM $+4 \mathrm{~mm}$ Al backplate. (a) The bottom of the ceramic conoid. (b) The top of the ceramic conoid. (c) Residual bullet. (d) The back of the aluminum backplate. (e) The front of the aluminum plate.

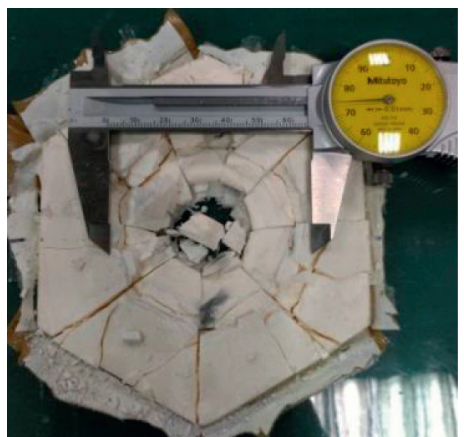

(a)

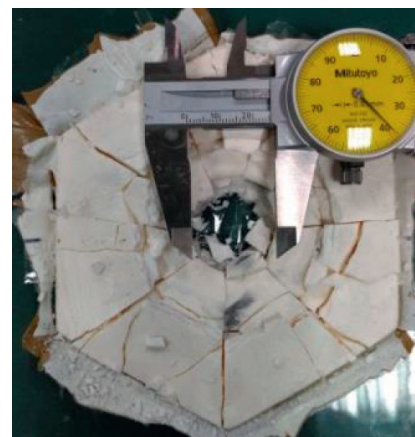

(b)

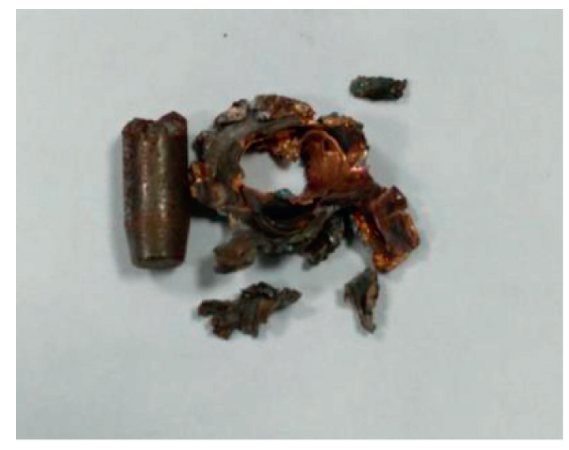

(c)

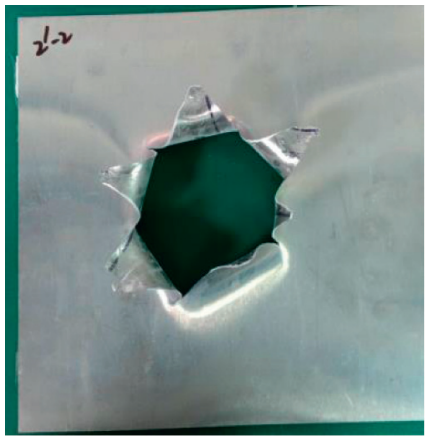

(d)

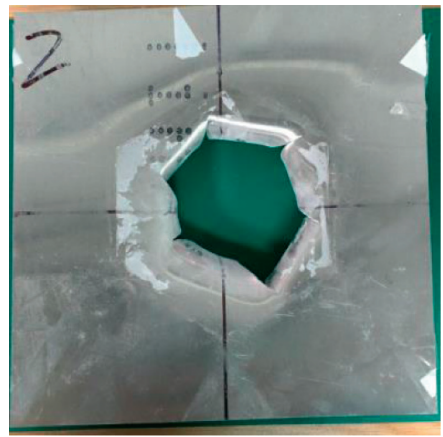

(e)

Figure 9: 10\% 333 FGM +1 mm Al backplate. (a) The bottom of the ceramic conoid. (b) The top of the ceramic conoid. (c) Residual bullet. (d) The back of the aluminum backplate. (e) The front of the aluminum plate. 


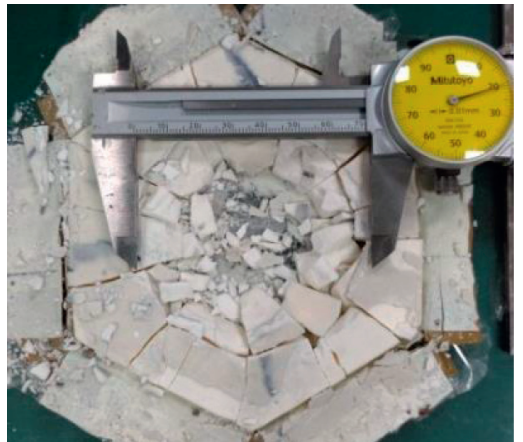

(a)

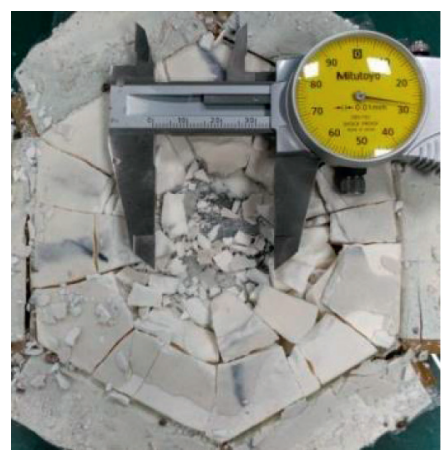

(b)

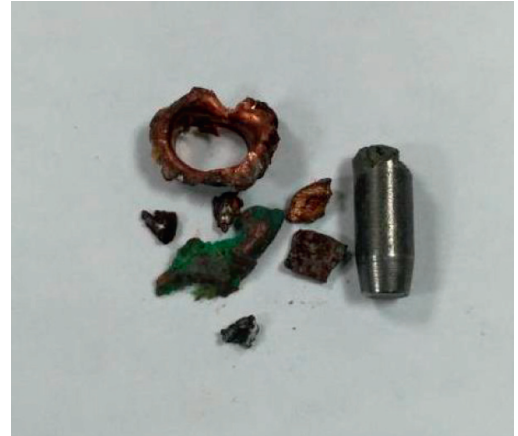

(c)

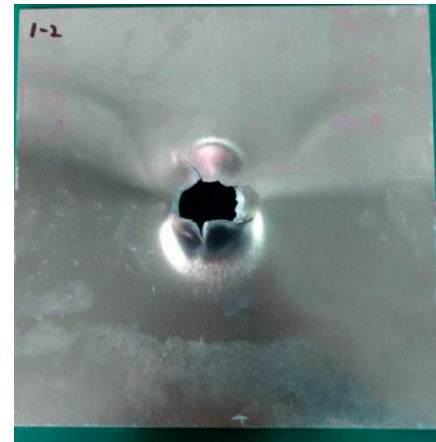

(d)

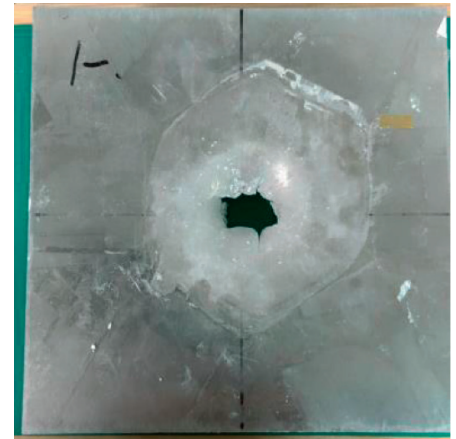

(e)

FIGURE 10: 5\% 333 FGM +4 mm Al backplate. (a) The bottom of the ceramic conoid. (b) The top of the ceramic conoid. (c) Residual bullet. (d) The back of the aluminum backplate. (e) The front of the aluminum plate.

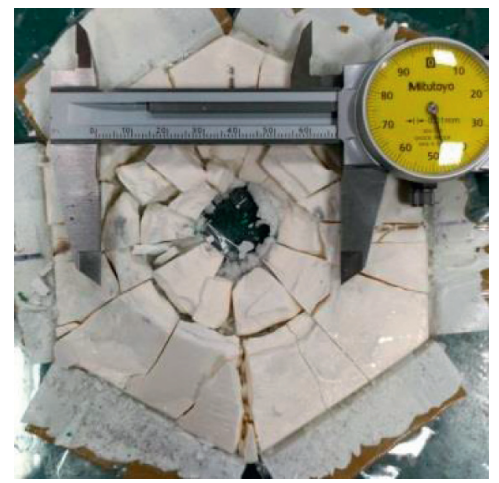

(a)

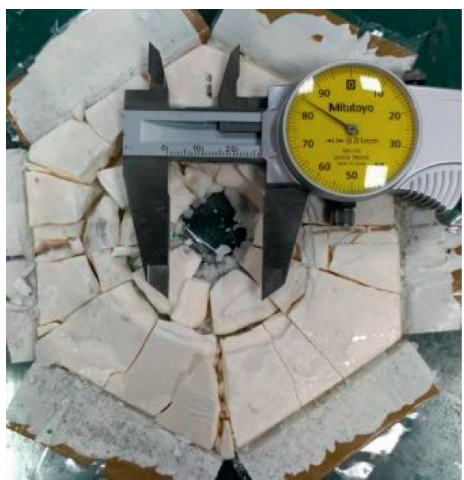

(b)

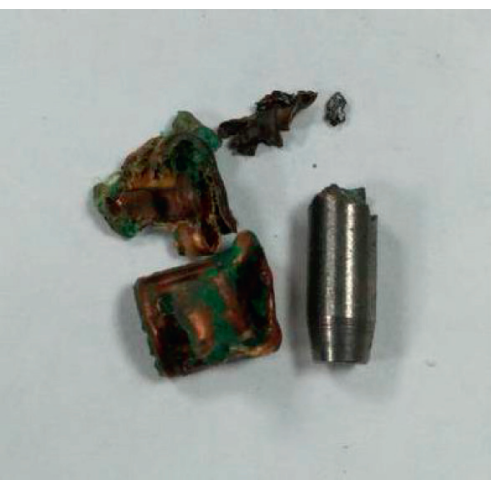

(c)

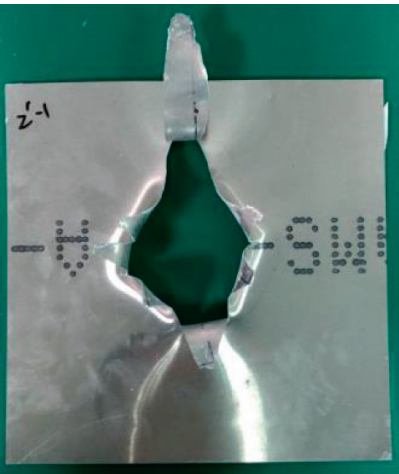

(d)

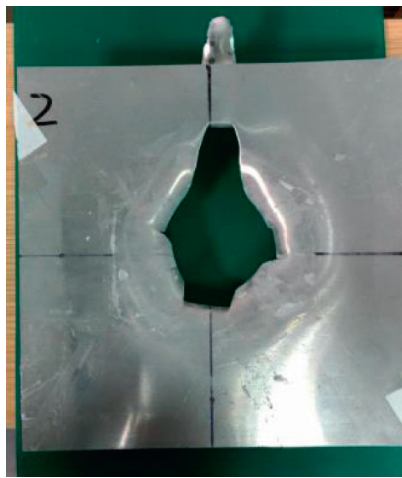

(e)

FIGURE 11: 5\%333 FGM + 1 mm Al backplate. (a) The bottom of the ceramic conoid. (b) The top of the ceramic conoid. (c) Residual bullet. (d) The back of the aluminum backplate. (e) The front of the aluminum plate. 
TABle 3: Parameters of the materials of each layer of the ceramic structure [9].

\begin{tabular}{|c|c|c|c|c|}
\hline Material & $\begin{array}{c}\rho_{C} \\
\text { density }\left(\mathrm{g} / \mathrm{cm}^{3}\right)\end{array}$ & $\begin{array}{c}E_{C} \\
\text { elastic modulus }(\mathrm{GPa})\end{array}$ & $\begin{array}{c}v \\
\text { Poisson's ratio }\end{array}$ & $\begin{array}{c}Y_{C 0} \\
\text { dynamic compressive strength }(\mathrm{GPa})\end{array}$ \\
\hline $100 \% \mathrm{Al}_{2} \mathrm{O}_{3}$ & 3.93 & 392 & 0.24 & 3.63 \\
\hline $95 \% \mathrm{Al}_{2} \mathrm{O}_{3} / 5 \% \mathrm{ZrO}_{2}$ & 4.04 & 379 & 0.24 & 3.86 \\
\hline $90 \% \mathrm{Al}_{2} \mathrm{O}_{3} / 10 \% \mathrm{ZrO}_{2}$ & 4.14 & 370 & 0.25 & 4.07 \\
\hline $80 \% \mathrm{Al}_{2} \mathrm{O}_{3} / 20 \% \mathrm{ZrO}_{2}$ & 4.35 & 358 & 0.25 & 3.77 \\
\hline
\end{tabular}

TABLe 4: Parameters of the material for AP models [9].

\begin{tabular}{lccccc}
\hline Material & $\begin{array}{c}\rho_{P} \\
\text { density }\left(\mathrm{g} / \mathrm{cm}^{3}\right)\end{array}$ & $\begin{array}{c}E_{P} \\
\text { elastic modulus } \\
(\mathrm{GPa})\end{array}$ & $\begin{array}{c}v \\
\text { Poisson's ratio }\end{array}$ & $\begin{array}{c}Y_{P} \\
\text { dynamic yield } \\
\text { strength }(\mathrm{GPa})\end{array}$ & $\begin{array}{c}L_{0} \\
\text { bullet length bullet diameter } \\
(\mathrm{cm})\end{array}$ \\
\hline $0.30^{\prime \prime}$ flat-nose AP bullet model & 7.89 & 202 & 0.3 & 1.7 & 2.808 \\
Flat-nose AP steel core model & 7.89 & 202 & 0.3 & 1.7 & 0.78 \\
\hline
\end{tabular}

TABle 5: Parameters of the material for Al backplate models [9].

\begin{tabular}{lccc}
\hline \multirow{2}{*}{ Material } & $\rho_{b}$ & $Y_{b}$ & $L_{0}$ \\
& density $\left(\mathrm{g} / \mathrm{cm}^{3}\right)$ & dynamic yield strength $(\mathrm{GPa})$ & 4 \\
\hline 6061 -T6 & 2.7 & 0.31 & plate thickness $(\mathrm{cm})$ \\
6061 -T6 & 2.7 & 0.31 & 1 \\
\hline
\end{tabular}

TABLE 6: Parameters of the trial plates using functionally graded ceramics.

\begin{tabular}{|c|c|c|c|}
\hline Material & $\begin{array}{c}\rho_{C} \\
\text { density }\left(\mathrm{g} / \mathrm{cm}^{3}\right)\end{array}$ & $\begin{array}{c}E_{C} \\
\text { elastic modulus }(\mathrm{GPa})\end{array}$ & $\begin{array}{c}Y_{C 0} \\
\text { dynamic compressive strength }(\mathrm{GPa})\end{array}$ \\
\hline $10 \% 333 \mathrm{FGM}$ & 4.14 & 372.81 & 3.82 \\
\hline $5 \% 333$ FGM & 4.04 & 380.12 & 3.85 \\
\hline
\end{tabular}

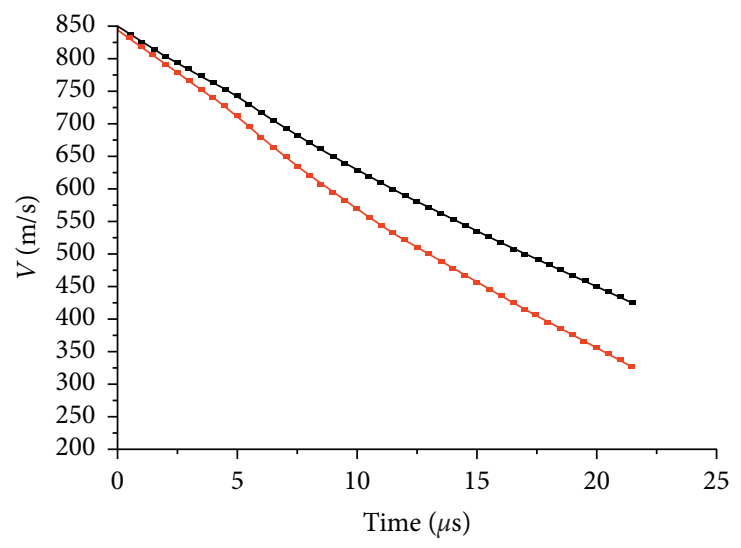

$-0.30^{\prime \prime}$ flat-nose bullet models
$=$ Steel-core flat-nose bullet models

FIgURE 12: Velocity-time diagram of the bullet (10\% 333 FGM $+4 \mathrm{~mm}$ Al backplate). 


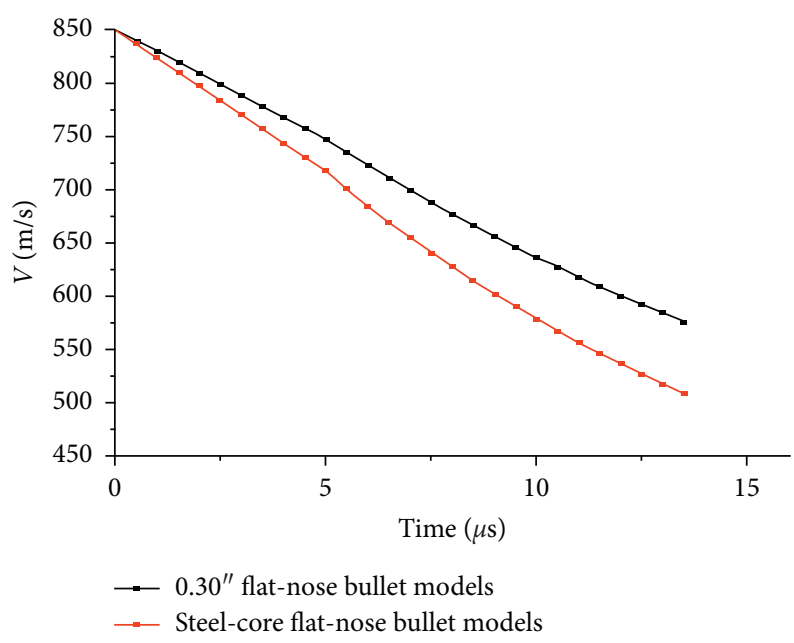

FIGURE 13: Velocity-time diagram of the bullet (10\% 333 FGM + $1 \mathrm{~mm}$ Al backplate).

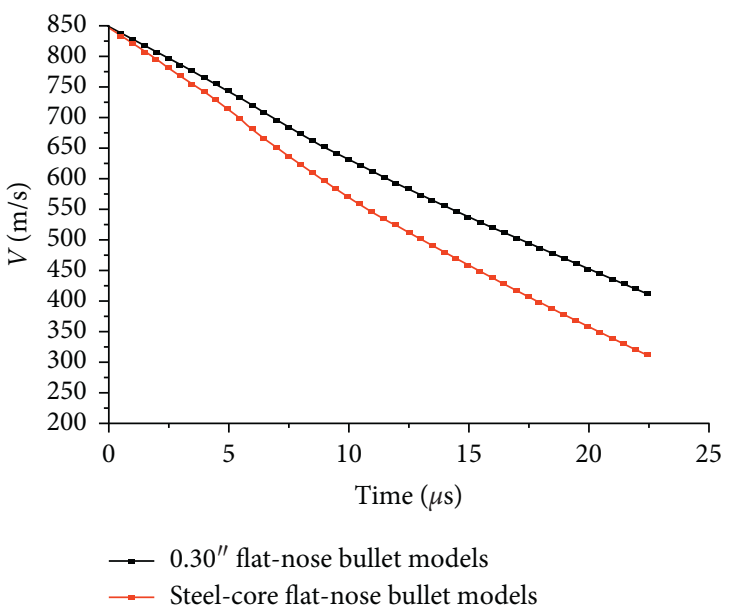

Figure 14: Velocity-time diagram of the bullet (5\% 333 FGM +

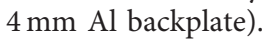

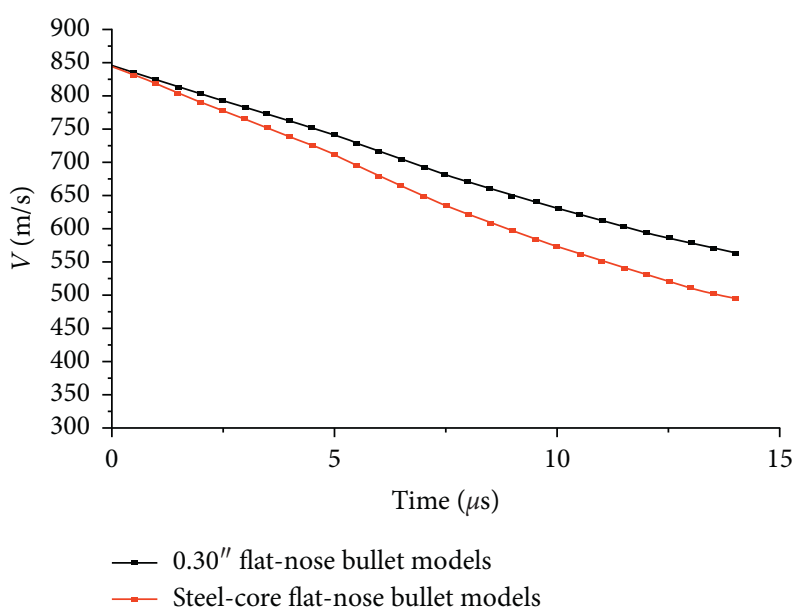

Figure 15: Velocity-time diagram of the bullet (5\% 333 FGM +

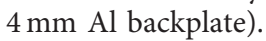

the error between the theoretical and experimental values was larger because of two reasons as follows. First, in the theoretical model, the erosion of the bullet was completed in the first stage, which was irrelevant to the thickness of the aluminum alloy backplate, and after the first stage, the bullet was no longer eroded. However, the experimental values revealed that the mass of the residual bullet was related to the thickness of the aluminum alloy backplate. When collecting the residual bullet, only the relatively complete steel core could be gathered, whereas the broken pieces of the copper jacket could not be easily collected. Consequently, the mass of the residual bullet collected was lower than the original residual mass, resulting in errors between theoretical and experimental models.

In addition, the residual velocities in Table 7 and the residual masses in Table 8 reveal that the theoretical residual velocities were higher than the experimental values. The reason was that in the theoretical model, the velocity changes in the bullets were related to the lengths (and the masses) of the bullets. After the first stage, the residual lengths (and masses) of the bullets were no longer reduced from erosion, and their residual masses were higher than those of the experimental results. Therefore, the theoretical residual velocities were also higher than those of the experimental results.

5.3. Comparisons of the Plug and Petal Types on the Metal Backplate. In theory, two failure types can be observed on the metal backplate, the plug type and the petal type. The ballistic experimental results are shown in Figure 16. To verify whether the theoretical analysis was correct, the masses of the aluminum backplates before and after the shooting were compared (Table 9). The comparison results revealed that when the aluminum alloy backplate was $4 \mathrm{~mm}$ in thickness, its mass was reduced by 2 grams after the shooting, indicating that the stretching, bending, deformation, and extrusion caused mass loss. However, when the backplate was $1 \mathrm{~mm}$ thick, no mass loss was observed after the shooting. Therefore, it is reasonable for this study to separate the aluminum alloy backplates into two categories in the theoretical analysis. 
Table 7: Comparison of residual velocities.

\begin{tabular}{|c|c|c|c|c|c|c|c|c|}
\hline \multirow[b]{2}{*}{ No. } & \multirow[b]{2}{*}{ Target plate } & \multicolumn{2}{|c|}{ Ballistic experiment } & \multicolumn{5}{|c|}{ Theoretical model } \\
\hline & & $\begin{array}{l}\text { Average initial } \\
\text { velocity }(\mathrm{m} / \mathrm{s})\end{array}$ & $\begin{array}{c}\text { Average } \\
\text { residual } \\
\text { velocity }(\mathrm{m} / \mathrm{s})\end{array}$ & $\begin{array}{l}\text { Initial } \\
\text { velocity } \\
(\mathrm{m} / \mathrm{s})\end{array}$ & $\begin{array}{c}\text { Residual velocity of the } \\
0.30^{\prime \prime} \text { flat-nose AP } \\
\text { model }(\mathrm{m} / \mathrm{s})\end{array}$ & $\begin{array}{c}\text { Error } \\
(\%)\end{array}$ & $\begin{array}{c}\text { Residual velocity of the } \\
\text { flat-nose steel core AP } \\
\text { model }(\mathrm{m} / \mathrm{s})\end{array}$ & $\begin{array}{c}\text { Error } \\
(\%)\end{array}$ \\
\hline 1 & $\begin{array}{c}10 \% 333 \mathrm{FGM}+ \\
4 \mathrm{~mm} \mathrm{Al} \\
\text { backplate }\end{array}$ & 844 & 301.7 & 844 & 425 & 29.01 & 327 & 7.74 \\
\hline 2 & $\begin{array}{c}10 \% 333 \text { FGM + } \\
1 \mathrm{~mm} \mathrm{Al} \\
\text { backplate }\end{array}$ & 850.7 & 489.9 & 850.7 & 576 & 14.95 & 508 & 3.56 \\
\hline 3 & $\begin{array}{c}5 \% 333 \mathrm{FGM}+ \\
4 \mathrm{~mm} \mathrm{Al} \\
\text { backplate }\end{array}$ & 847.7 & 297.9 & 847.7 & 412 & 27.69 & 311 & 4.21 \\
\hline 4 & $\begin{array}{c}5 \% 333 \mathrm{FGM}+ \\
1 \mathrm{~mm} \mathrm{Al} \\
\text { backplate }\end{array}$ & 842.8 & 473.7 & 842.8 & 562 & 15.71 & 494 & 4.11 \\
\hline
\end{tabular}

TABLE 8: Bullet residual mass comparisons.

\begin{tabular}{lcccc}
\hline \multirow{2}{*}{ No. } & Target plate & $\begin{array}{c}\text { Initial bullet mass (steel) } \\
(\mathrm{g})\end{array}$ & $\begin{array}{c}\text { Residual bullet mass (steel) } \\
(\mathrm{g})\end{array}$ & $\begin{array}{c}\text { Theoretical residual bullet mass } \\
(\mathrm{g})\end{array}$ \\
\hline 1 & 10\% 333 FGM + 4 mm Al backplate & 5.187 & 3.379 & 4.25 \\
2 & $10 \%$ 333 FGM + 1 mm Al backplate & 5.187 & 3.783 & 4.24 \\
3 & $5 \%$ 333 FGM + 4 mm Al backplate & 5.187 & 3.549 & 4.24 \\
4 & $5 \%$ 333 FGM + 1 mm Al backplate & 5.187 & 3.787 & 4.25 \\
\hline
\end{tabular}

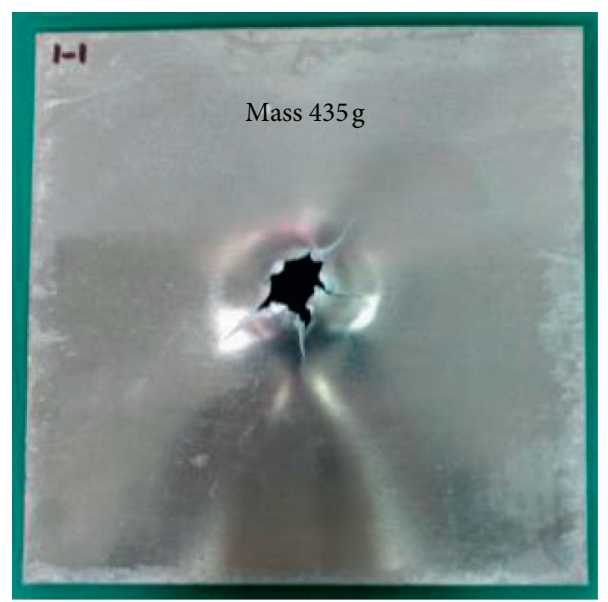

(a)

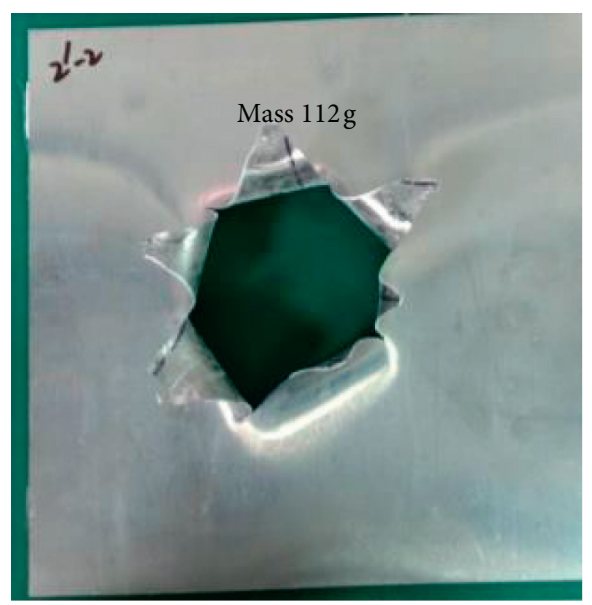

(b)

Figure 16: Continued. 


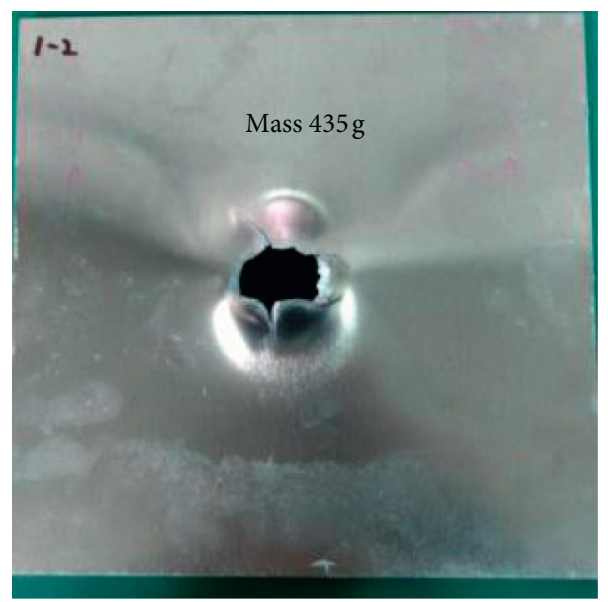

(c)

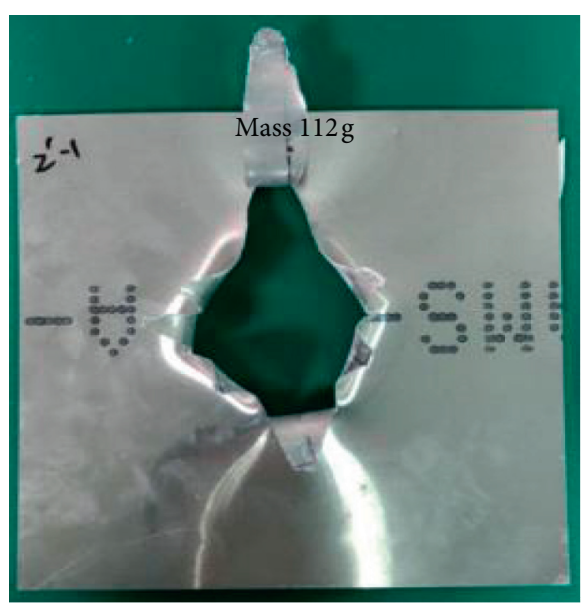

(d)

FIGURE 16: Mass of the aluminum alloy backplate after the ballistic experiments. (a) $10 \% 333 \mathrm{FGM}+4 \mathrm{~mm}$ Al backplate. (b) $10 \% 333 \mathrm{FGM}+$ $1 \mathrm{~mm}$ Al backplate. (c) 5\% 333 FGM $+4 \mathrm{~mm}$ Al backplate. (d) $5 \% 333 \mathrm{FGM}+1 \mathrm{~mm}$ Al backplate.

TABLE 9: Aluminum alloy backplate mass comparison.

\begin{tabular}{|c|c|c|c|c|}
\hline No. & Target plate & $\begin{array}{l}\text { Initial mass of the aluminum alloy } \\
\text { backplate }(\mathrm{g})\end{array}$ & $\begin{array}{l}\text { Residual mass of the aluminum alloy } \\
\text { backplate }(\mathrm{g})\end{array}$ & $\begin{array}{l}\text { Difference } \\
(\mathrm{g})\end{array}$ \\
\hline 1 & $\begin{array}{c}10 \% 333 \mathrm{FGM}+4 \mathrm{~mm} \mathrm{Al} \\
\text { backplate }\end{array}$ & 437 & 435 & -2 \\
\hline 2 & $\begin{array}{c}10 \% 333 \mathrm{FGM}+1 \mathrm{~mm} \mathrm{Al} \\
\text { backplate }\end{array}$ & 112 & 112 & 0 \\
\hline 3 & $\begin{array}{l}5 \% 333 \mathrm{FGM}+4 \mathrm{~mm} \mathrm{Al} \\
\text { backplate }\end{array}$ & 437 & 435 & -2 \\
\hline 4 & $\begin{array}{l}5 \% 333 \mathrm{FGM}+1 \mathrm{~mm} \mathrm{Al} \\
\text { backplate }\end{array}$ & 112 & 112 & 0 \\
\hline
\end{tabular}

\section{Conclusion}

This study integrated bullet erosion, cracking of ceramic materials, and the deformation of metal backplates to establish a theoretical model of a bullet perpendicularly impacting a functionally graded ceramic-aluminum alloy target plate. The predictions of the model were compared with experimental results, and the conclusions are as follows:

(1) Two theoretical failure types of the metal backplates were established: the petal type, which is applicable when the backplate was between $1 \mathrm{~mm}$ and $3 \mathrm{~mm}$ thick, and the plug type, which is applicable when the backplate was $4 \mathrm{~mm}$ thick or thicker. Ballistic experimental results revealed that the thicker the aluminum backplate was, the more substantial the extrusion was.

(2) Multiple 0.30" AP bullets were utilized in the ballistic experiments. The results from the theoretical models using flat-nose steel core bullets were closer to the experimental results than using $0.30^{\prime \prime}$ flat-nose AP bullets (with full bullet mass). The reason was that when the bullet hit the target plate, its copper jacket immediately deformed, cracked, and was separated from the steel core. Because most of the copper remained in the front of the target plate, the destruction caused by the bullet to the target plate was weakened and the theoretical result was deviated from the experimental results.

(3) The residual bullets from the ballistic experiments were observed. The front of the steel core of the bullet was eroded during the impact, resulting in mass loss. The phenomenon was in line with the inference from the theoretical model; namely, that because of erosion, the bullet became shorter in length and smaller in mass.

(4) The functionally graded ceramic-aluminum alloy material theoretical model established by this study demonstrated an average error of less than $10 \%$ from the experimental results, reflecting the credibility and usefulness of the model. This model could also be applied to general ceramic-metal material structures to predict the residual velocity of a flatnose bullet penetrating such structures.

\section{Data Availability}

The table/figures data used to support the findings of this study are included within the article. 


\section{Conflicts of Interest}

The authors declare that they have no conflicts of interest regarding the publication of this paper.

\section{Acknowledgments}

The authors thank all the graduate students in the ballistic laboratory for their wholehearted support in the experimental tests and material manufacturing process.

\section{References}

[1] E. Medvedovski, "Ballistic performance of armour ceramics: influence of design and structure. Part 1," Ceramics International, vol. 36, no. 7, pp. 2103-2115, 2010.

[2] A. Tate, "A theory for the deceleration of long rods after impact," Journal of the Mechanics and Physics of Solids, vol. 15, pp. 387-399, 1966.

[3] A. Tate, "Further results in the theory of long rod penetration," Journal of the Mechanics and Physics of Solids, vol. 17, pp. 141-150, 1969.

[4] V. P. Alekseevskii, "Penetration of a rod into a target at high velocity," Combustion, Explosion and Shock Waves, vol. 2, no. 2, pp. 99-106, 1966.

[5] M. L. Wilkins, "Mechanics of penetration and perforation," International Journal of Impact Engineering, vol. 16, pp. 793807, 1978.

[6] P. C. Den Reijer, Impact on ceramic faced armours, Ph.D. dissertation, Delft University of Technology, Delft, The Netherlands, 1991.

[7] R. Zaera and V. S. Galvez, "Analytical modeelling of normal and oblique ballistic impact on cermic metal lightweight armours," International Journal of Impact Engineering, vol. 21, pp. 133-148, 1998.

[8] R. L. Woodward, R. G. O’Donnell, B. J. Baxter, B. Nicol, and S. D. Pattie, "Energy absorption in the failure of ceramic composite armours," Materials Forum, vol. 13, pp. 174-181, 1989.

[9] C. Y. Huang, Impact resistant analysis of funtionally graded ceramic composite, Ph.D. thesis, Chung Cheng Institute of Technology, National Defense University, Taoyuan City, Taiwan, 2017. 